\title{
A NanoSIMS study of micro- distribution of carbon isotope in ureilite meteorites
}

Yunbin Guan1, TaE Eun Hongr, Mi-Rang Byeon2, AND JOHN EILER1

1California Institute of Technology, Pasadena, CA, USA

${ }_{2}$ Korean Basic Science Institute, Busan, Korea

Ureilites are ultramafic meteorite samples composed mainly of coarse-grained olivine and pyroxene with finegrained carbonaceous interstitial materials (often referred to as C-matrix). They constitute the second largest group of achondritic meteorites, with paradoxical petrological characteristics and an enigmatic origin. Bulk $\mathrm{C}$ isotopic compositions of ureiltes suggest a large $(>1000 \mathrm{~km}$ in diameter) and unique ureilite parent body (UPB) with a mantle that has two $\mathrm{C}$-rich reservoirs of distinctive $\mathrm{Fe} / \mathrm{Mg}$ ratios, $\mathrm{C}$ and $\mathrm{O}$ isotopic compositions. However, the $\mathrm{O}$ isotopic compositions of ureilites indicate the preservation of original geochemical signatures from the heterogeneous nebula that are inconsistent with planetary-scale igneous differentiation of a large parent body.

Carbon reduction (smelting) of olivine and pyroxene is ubiquitous in all ureilite samples. It is possbible that bulk data do not reflect the true micro-distribution nature of $\mathrm{C}$ isotope of ureilites. If the $\mathrm{C}$-reduction process could fractionate $\mathrm{C}$ isotope, then the large variation of $\mathrm{C}$ isotopic compositions among different ureilite samples could be resulted from various degrees of $\mathrm{C}$ reduction. There would be no need to invoke two C-reservoirs for UPB. If no obvious C isotopic fractionation can be observed between the $\mathrm{C}$-matrices and reduction rims in ureilites, then different $\mathrm{C}$ isotopic sources on UPB need to be considered.

Two repesentative ureilite samples (Kenna and Goalpara) have been investigated for this work. Several standards (graphite, charcoal, 1-Hydroxybenzotriazole, and the C905 organic carbon) are used to assess possible matrix effects for $\mathrm{C}$ isotope analysis with NanoSIMS. The overal analytical precision is $\sim \pm 3 \%$ o $(2 \sigma)$. Three amorphous graphite areas have $\delta{ }_{13} \mathrm{C}$ values between -11 to $-14 \%$; whereas three euhedral graphites in olivine reduction rims show $\delta 13 \mathrm{C}$ values between -4 to $-7 \%$. The distiguishable difference in the $\delta_{13} \mathrm{C}$ vaules of graphites from the two distinctive occurrences suggests $\mathrm{C}$ reduction in individual ureilite can indeed fractioante $\mathrm{C}$ isotope. The large variarion in bulk $\mathrm{C}$ isotopic compositions of ureilites probably does not indicate two Creservoirs on UPB. 